\title{
Editorial
}

\section{Carbide Ripened Fruits- A Recent Health Hazard}

\author{
SA Fattah ${ }^{1}$, MY Ali $^{2}$
}

Large amount of tropical fruits are produced in this subcontinent including Bangladesh. But in recent times consumption of fruits becomes extremely hazardous due to artificial ripening of fruits by different toxic chemical agents. Normally fruits produce a ripening hormone ethylene that induces the natural process of maturation. This process is artificially accelerated by using different chemicals of which calcium carbide is the commonest. Calcium carbide in contact with moisture produces acetylene which is an analogue of natural ripening hormone ethylene. Acetylene is a highly reactive substance used mainly in welding and allied industries. Industrial grade calcium carbide also contains trace amounts of more toxic arsenic and phosphorous that converts the healthy fruits poisonous ${ }^{1}$.

Calcium carbide is used as ripening agent for mangoes, bananas, jackfruits, litchis and other fruits also. Packets of calcium carbide powder are kept in the container of fruits where in contact with moisture, acetylene gas is produced and acts as a ripening agent. Traders pick green fruits before maturation, ripen artificially to serve in the market earlier than the season for higher profit .Moreover green fruits are transported easily with minimum damage and ripened at the place of retail sell.

Consumption of carbide ripened fruits is extremely hazardous for health, mainly for the nervous system. Acetylene, generated from carbide reduces oxygen supply to the brain. In acute stage, it causes headache, vertigo, dizziness, delirium, seizure and even coma. In the long term, it may produce mood disturbance and loss of memory ${ }^{2}$. Immediately after consumption, there may be abdominal pain, vomiting and diarrhoea. It is reported from Lahan Hospital, Nepal that around 30-40 patient are treated there daily for abdominal symptoms

1. Dr. Sk. Abdul Fattah, DTCD, FCPS (Medicine), Assistant Professor, Dept. of Medicine, FMC, Faridpur.

2. Dr. Md. Yusuf Ali, FCPS (Medicine), Associate Professor, Dept. of Medicine, FMC, Faridpur. caused by consumption of carbide-ripened mangoes ${ }^{3}$.Other toxic effects include skin burn, allergy, jaundice and carcinogenic potential ${ }^{3}$.

Precautionary measures to avoid toxic effects to some extent are through washing of fruits before eating and not to eat skin of fruits. Even better option is to buy mature fruits directly from growers and to ripen it at home in warm temperature in contact with one ripe fruit.

Bangladesh pure food ordinance 2005 prohibits use of any poisonous chemical like calcium carbide, formalin, pesticides or toxic colour/ flavour in any food that may cause harm to human body ${ }^{4}$. The Bangladesh high court recently issued some directives to the government to stop this practice ${ }^{5}$ and some administrative drives are also been taken. Despite this legal prohibition, chemically treated fruits are selling openly in all markets and ripening agents are also available.

Department of environment need to be activated with proper authority and strength. Administrative actions should be reinforced more vigorously. Above all, due attention should be given to build awareness among traders and consumers.

\section{References}

1. Kader AA. Post harvest Technology of Horticulture Crops. University of California 2002; p.157.

2. "Nepal: People eating carbide-ripened mangoes fall ill." www.21 food.com/news/detail27823.html. (Accessed on 06/06/2010)

3. "Calcium carbide poisoning via food in childhood". www.ncbi.gov/pubmed/17307629 (Accessed on 06/06/2010)

4. The Daily Star, 5th June, 2010.

5. "Toxic chemicals for ripening fruits". The New Age, 18th May, 2010. 